International Research Journal of Management, IT \& Social Sciences
Available online at https://sloap.org/journals/index.php/irjmis/
Vol. 7 No. 2, March 2020, pages: 38-43
ISSN: 2395-7492
https://doi.org/10.21744/irjmis.v7n2.868

\title{
Plan of Psychological Actions for Anger Control in Taekwondo
} Athletes

\author{
CrossMark
}

Carelia Serrano Abalos ${ }^{a}$

Osvaldo Jiménez Pérez de Corcho ${ }^{\text {b }}$

\section{Article history:}

Submitted: 18 January 2020

Revised: 27 February 2020

Accepted: 04 March 2020

\section{Keywords:}

anger;

expression;

intervention;

negative evaluation;

psychological;

\begin{abstract}
The present investigation has carried out intending to design a plan of psychological actions that contributes to the control of anger in athletes of the Taekwondo school category of the EIDE «Captain Orestes Acosta» of Santiago de Cuba. For this, a diagnosis of the state of anger and its expression has made to ten athletes of that category, with the application of observations, interviews and the expression inventory of Ira Trago-Estado, child-adolescent version. The experience of anger has described, describing the situations and related thoughts, where the efforts and/or resources of the athletes are not sufficient, effective or adequate for their control. This diagnosis made possible the elaboration of the plan with actions designed for the evaluation and adequate response to the situations that have propitiated in the course of the preparation and the competences.
\end{abstract}

International research journal of management, IT and social sciences (C) 2020. This is an open access article under the CC BY-NC-ND license (https://creativecommons.org/licenses/by-nc-nd/4.0/).

Corresponding author:

Carelia Serrano Abalos,

Universidad de Oriente, Santiago de Cuba, Cuba.

Email address: carelia.serrano@infomed.sld.cu

${ }^{a}$ Universidad de Oriente, Santiago de Cuba, Cuba

b Universidad Técnica de Manabí, Portoviejo, Ecuador 


\section{Introduction}

The current conditions of modern sport and the high demands imposed by its competency system generate increasing demands on athletes to be successful in the development of their activity. These demands involve the mobilization of greater neurophysiological, technical, tactical and psychological resources. In the sense of psychological resources, affective processes and in particular emotions occupy a special place, considering their intense expression during sports training and competitions.

Since its inception, psychology has been concerned with the study of emotions. In the research of psychology applied to sports, numerous studies have developed to expose the influence of emotions on athletes (Hardy, 1996; Jones, 2003, cited in Cisneros, 2016). In our country, works published by González (2001, 2004), García (2004) and Cañizares (2004), are a reference among researchers. However, anger has been one of the least referred emotions in the scientific literature consulted, with anxiety, pre-start states, and stress being the most studied. Research conducted on this topic has aimed at determining differences in anger levels based on certain types of sport and sports level, based on the comparison between groups of the results obtained (González-García et al., 2017; Menéndez \& Fernández-Rio, 2015).

These authors resume the study of anger in an investigation with table tennis players correlating control locus with performance and anger. In it, they consider anger as an important variable in the sport performance of table tennis and its necessary control to achieve higher levels of performance. Finally, between the lines of future proposals they recommend working strategies for the external control of anger in the players of this sport because of the relationship, it presents with performance (González-García et al., 2017).

Other authors propose to describe the extent to which this emotion can benefit performance in combat sports. From this perspective, it has proposed to evaluate in athletes who practice Judo, if the expression of anger they experience has related to their performance, identify the beliefs of these athletes about the usefulness of anger for the achievement of successes in their competitions and the effect of these about expressing the emotion of anger and performance. This research focused on the correlation between the variables defined in correspondence with their objectives and the instruments used (Oliva-Mendoza et al., 2011).

When analyzing the influence of anger on sports performance, it has considered that it can be positive or negative. In the EIDE «Captain Orestes Acosta» high-performance provincial center of Santiago de Cuba, an investigation has carried out to develop a plan of psychological intervention aimed at favoring the regulation of negative emotional states in badminton athletes for competitions. In this plan, group work sessions were designed in the form of experiential workshops for reflection among participants about their emotional states, in particular anxiety, psychic tension, fear of failure and anger, and the latter in one of the sessions (Espinosa et al., 2018; Singh \& Parmar, 2016). Often, in the psychological preparation that is carried out with athletes in the EIDE «Captain Orestes Acosta» in the province of Santiago de Cuba, special attention is given to the control of emotional states in the precompetitive and competitive stages, with emphasis on the states of reboot and anxiety in particular. For the sport of Taekwondo, specifically, in the psychological preparation plans the study of the manifestations of the emotional states in correspondence with the variations that have presented according to the characteristics of the microcycles of the preparation, learning, and adaptation of the mechanisms of self-control and self-regulation of these states. Proposed in a general way, to be attended in practice according to the main needs presented.

The application during the preparatory and competitive periods of the method of observation to training and competitions of the school category, interviews with athletes and coaches and assessment scales reflected the frequent manifestation of negative emotions of anger, frustration, and irritability in different activities training and skills. Which sometimes constitute habitual responses to any situation and in others an exaggerated response to the stimulus that gave rise to it. Besides, in the work on the subject of emotions, difficulties arise for the understanding of their manifestations. In the analysis of the Comprehensive Athlete Preparation Program, it is necessary to highlight that this document presents general aspects that cover physical, technical preparation at different levels of development determined for this sport, general, and educational objectives, methodological indications among others related to regulations and competitions. In the subject of psychological preparation, the treatment of emotional states in the stated objectives or the limited contents of the preparation has not specified.

Based on the diagnosis made with the Taekwondo athletes. The consultation of the scientific literature and the revision of the Comprehensive Athlete Preparation Program has assessed as a problematic situation that the presence of the mentioned manifestations of anger in athletes motivates the approach of psychological interventions to the control of this emotion. That allows them an adequate response to the situations that have propitiated in the course of their preparation and the competences. Based on which, the objective of this research is to design a plan of

Abalos, C. S., \& Corcho, O. J. P. de. (2020). Plan of psychological actions for anger control in taekwondo athletes. International Research Journal of Management, IT and Social Sciences, 7(2), 38-43. https://doi.org/10.21744/irjmis.v7n2.868 
psychological actions that contributes to the control of anger in athletes in the Taekwondo school category of the EIDE «Captain Orestes Acosta» of Santiago de Cuba.

\section{Materials and Methods}

A mixed methodology was used to out the research; qualitative-quantitative; being a descriptive investigation of the cross-section. Which has developed with 10 weightlifting athletes of category 15-16 of the EIDE of Santiago de Cuba, in the period corresponding to the training macrocycle of 2018 - 2019. In it, a diagnosis of the manifestations of fear was made to fail in these weightlifters during competitions (competitive modeling, stops, events and national school games) and how it affected the performance of these athletes. Subsequently, a proposal for psychological intervention actions is developed and applied to diagnose and assess the effectiveness of the proposal, taking into account how it influenced the management and control of this fear of failure.

An investigation has conducted with a mixed methodology: qualitative-quantitative, which corresponds from its design to the type of descriptive, cross-sectional study; this allows informing how anger manifests in athletes and the evaluation of the components of this emotion. It has developed with 10 Taekwondo athletes from the EIDE Orestes Acosta school category of Santiago de Cuba, in the period corresponding to the 2018-2019 training macrocycle. From the diagnosis of the state of anger and its expression, a technique is developed and applied psychological intervention action plan. The effectiveness of the same will be evaluated later taking into account the changes registered in athletes.

In the investigation, observations have made to the training sessions, stops, and key competencies to identify the manifestations of anger in the behavior of athletes. With the conduct of interviews with these athletes, the forms of anger expression in the athletes have evaluated, identifying the contexts in which they manifest themselves and related thoughts. While with the application of the State-Trait Expression Inventory (STAXI-II; N / A) Child-adolescent version, anger was assessed as a trait and as a state, its forms of expression and its control in the child-youth population.

\section{Results and Discussions}

The main manifestations of anger observed in training situations and competitions consisted of protests, the disorganized performance of various kicking or punching techniques without being effective and/or away, isolating, rejecting contact with others and throw objects. In the interviews, the experiences of anger are linked to situations such as arbitration decisions and penalties, whether unfavorable to the athlete or favorable to the contrary, improper manipulation of the marker by the judges, provocations of the contrary, other athletes participating in the competition or people from the public. Repeated actions of the opponent in the exchange such as grabbing or hitting the legs that have not penalized difficulties in developing certain actions on the adversary or criticism of classmates in training. These situations can occur in competitions, stops, and assaults of the training units.

Thoughts related to the aforementioned circumstances: negative evaluations of the arbitrator or arbitration in general, with the use of offensive language, blaming contrary to having a low technical level, retaliation, have ridiculed in front of others. Besides, expressions such as "they want to take away my combat", "others are unfair to me" or "everyone is against me". The forms of expression of this emotion, whether internalized or externalized, hurt the performance of athletes. The responses recorded in the observations and declared by them affect acts of indiscipline in the powers that may generate new penalties. When the experience of anger begins, the evaluations that the athlete continues to perform and that allow the maintenance and / or increase of emotional state affect the concentration of attention in combat and the organization of their actions.

Nine of the athletes (for $90 \%$ of the sample) experienced a high state of anger during the control activity, and a strong desire to express that state through words and / or through physical actions (hitting, throwing). Only one of them indicates a medium intensity in the experience of this emotion. The analysis of the Cala Trago - Anger - Reaction raises allows to verify that the analyzed emotion is experienced in situations that involve frustration that perceives a threat and/or negative evaluations. In cases like these, it has considered that they can be very sensitive to criticism, the perception of provocation or insults and negative evaluations issued by others. Frequently they may experience intense states of anger under such circumstances.

The responses of 7 athletes (corresponding to 70\%) point to the expression of internalized anger as the usual coping style, in which the experiences of anger are suppressed or repressed. That does not exclude the externalized expression of anger, directed towards others or objects in the environment. For three of the athletes in the investigation (30\%) this 
form of externalized expression of anger stands out. Anger control in athletes manifests itself in a medium-range so that the efforts and/or resources they make are not sufficient, effective or adequate.

The negative impact of the experience of anger on athletes and deficiencies for its proper management motivates the approach of psychological interventions for the control of this emotion that allows them an adequate response to the situations that have propitiated in the course of their preparation and skills. From this premise, a plan of psychological actions has proposed that contributes to the control of anger in athletes. The psychological action plan has developed from five actions distributed during the Special Preparation stage planned for training. Considering its content, each action has applied in several work sessions of approximately 50 minutes. In figure 1 , the actions taken have shown.

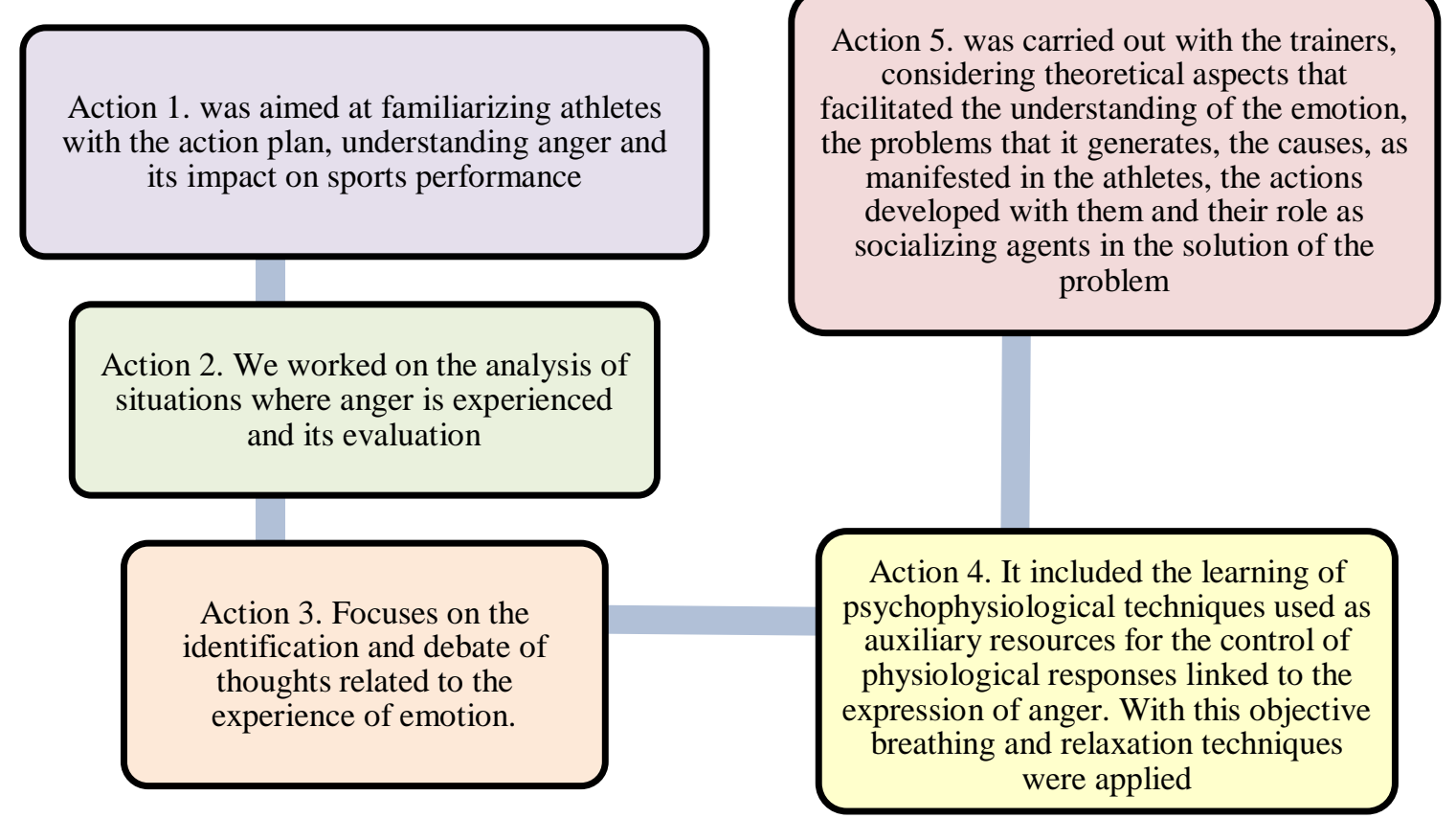

Figure 1. Actions were taken to improve performance improve the performance

These actions help to of the deporists, and with them, it has been evidenced how they advance in the quality process in sports.

\section{Conclusion}

a) The research carried out on this topic varies from the determination of differences in the levels of anger depending on certain types of sport, the correlation with other variables and the characterization of its effects on athletes.

b) The experience of anger has related to situations involving frustration, a perception of threat and / or negative assessments.

c) A plan of psychological actions was implemented where the appropriate evaluation of the situations that are propitiated during the preparation and the competencies with psychophysiological techniques are integrated to contribute to the control of anger in athletes of the EIDE Taekwondo school category « Captain Orestes Acosta »from Santiago de Cuba.

Abalos, C. S., \& Corcho, O. J. P. de. (2020). Plan of psychological actions for anger control in taekwondo athletes. International Research Journal of Management, IT and Social Sciences, 7(2), 38-43. https://doi.org/10.21744/irjmis.v7n2.868 
Conflict of interest statement

The authors declared that they have no competing interests.

Statement of authorship

The authors have a responsibility for the conception and design of the study. The authors have approved the final article.

Acknowledgments

We are grateful to two anonymous reviewers for their valuable comments on the earlier version of this paper. 


\section{References}

Cañizares, H. (2004). Psicología y equipo deportivo. Editorial Deportes.

Cisneros, M. (2016). Psychological intervention plan for anger control in baseball pitchers. Master's thesis, University of Physical Culture and Sports Sciences, Granma, Cuba.

Espinosa, A. H. R., Estevez, A. G., Roche, J. R. F., Figarola, Y. M., \& Rodriguez, D. L. (2018). Psychological intervention for development of disease awareness in addicts: Villa Colibri therapeutic community of Santiago de Cuba. International Journal of Health Sciences, 2(3), 72-80. https://doi.org/10.29332/ijhs.v2n3.232

García, F. (2004). Psychological tools for coaches and athletes. Havana City: Editorial Sports.

González, L. (2004). The emotional response of the athlete: a scientific vision of behavior in the face of the competitive challenge. Havana city. Editorial Sports.

González, L.G. (2001). Stress and high performance sport. Jalisco: Western Institute of Technology and Higher Education (ITESO).

González-García, H., Pelegrín, A., \& Carballo, J. (2017). Anger and tough personality in racket and endurance athletes. Ibero-American Journal of Physical Activity and Sports Sciences, 6 (2), 21-29. http://dx.doi.org/10.24310/riccafd.2017.v6i2.3776

Hardy, L. (1996). Testing the predictions of the cusp catastrophe model of anxiety and performance. The sport psychologist, 10(2), 140-156.

Jones, S. P. (Ed.). (2003). Haskell 98 language and libraries: the revised report. Cambridge University Press.

Menéndez, J., \& Fernández-Río, J. (2015). Levels of anger in boxing and kickboxing practitioners: differences depending on the discipline and sports level. Notebooks of Sports Psychology, 15 (3), 75-86.

Oliva, F., Calleja, N., \& Hernández, R. (2011). The anger in the sporting performance of judoka. Magazine Latin American Behavioral Medicine, 1 (2), 41-48.

Singh, A., \& Parmar, D. S. (2016). A comparative study of psychological factor among female athletes. International Research Journal of Engineering, IT \& Scientific Research, 2(1), 8-21.

Abalos, C. S., \& Corcho, O. J. P. de. (2020). Plan of psychological actions for anger control in taekwondo athletes. International Research Journal of Management, IT and Social Sciences, 7(2), 38-43. https://doi.org/10.21744/irjmis.v7n2.868 